\title{
Can Migraines be Effectively Managed with Combined Oral Contraceptives?
}

\section{Erica C. Dun ${ }^{1}$ and Jin Jun Luo ${ }^{2 *}$}

${ }^{1}$ Lankenau Medical Center, Wynnewood, USA

${ }^{2}$ Temple University School of Medicine, USA

\section{Editorial}

Women experience migraine headaches three times more often than men [1]. Migraine affects as many as $37 \%$ of reproductive-age women in the United States [2]. Migraines that occur during the menstrual cycles are resistant to treatment and lead to significant functional disability. Management of migraine in women has long been a clinical challenge.

A common belief about the cause of migraines in women is the fluctuation of the hormones estrogen and progesterone. In the normal menstrual cycle, estrogen rises rapidly during the first half, called the follicular phase, until mid-cycle where the levels dip prior to ovulation. Progesterone is only produced after ovulation. During the second half of the cycle, or luteal phase, the levels of both estrogen and progesterone fluctuate markedly. Estrogen rises again and progesterone increases until both peaks at day 23 , which is 5 days prior to menstruation. If no fertilization occurs, the levels of estrogen and progesterone rapidly fall. The fall in the estrogen can trigger menstrual-related migraine headaches. Similarly, women who take combined estrogen and progesterone oral contraceptives (COCs) often experience migraines during the hormone-free interval. The fall in the estrogen caused by taking the placebo pills can trigger migraines. According to the International Classification of Headache Disorders (ICHD-II), the estrogen-withdrawal headache is defined as "a headache or migraine that develops within 5 days after cessation of estrogen use and resolves within 3 days."

Migraines occur with or without an aura. Aura is usually a visual event occurring 5-60 minutes before the onset of headache. The visual aura is characterized by reversible symptoms such as a flickering uncolored zigzag line progressing laterally to the periphery of one visual field or laterally spreading scintillating scotomata. Several studies have associated a high risk of stroke in women who have migraines with aura $[3,4]$. The thought is that aura is associated with ischemic changes in the brain.

The underlying pathophysiology of migraine headaches is believed due to neurovascular dysfunction called cortical spreading depression. This phenomenon causes vasoconstriction, followed by rapid return to baseline vascular tone. Consequently, the process produces neuroinflammatory mediators that centrally sensitize and cause cutaneous allodynia, an exaggerated painful sensation due to a stimulus that does not normally provoke pain, and poor response to abortive treatment for migraine.

The first-line abortive treatments for migraines include nonsteroidal anti-inflammatory drugs (NSAIDS) and triptans. NSAIDS function via several mechanisms including inhibiting the enzyme cyclooxygenase and prostaglandin synthesis, enhancing adrenergic transmission through increasing norepinephrine release, and suppressing inflammation. Triptans bind to 5-HT1B and 5-HT1D receptors in cranial blood vessels, causing vascular smooth muscle vasoconstriction and inhibiting vasoactive peptide synthesis.
Unfortunately, in treatment of chronic migraineurs where the number of headache days is greater than 15 per month, neither NSAIDS nor triptans are used as a preventative therapy because of the limitations of their side effect profiles. For those patients, non-hormone medications such as the antidepressants, antiepileptic drugs, beta-blockers, and calcium channel blockers are frequently administrated but the responses are variable. For those women who suffer with chronic migraines and poorly respond to the non-hormone medication treatment, administration of COCs can effectively reduce the frequency of attacks by keeping their estrogen levels steady. This could be especially helpful for women suffering from menstrual-related migraines.

The administration of COCs has been proven effective in treating certain types of women migraineurs and is recommended in the practice guideline by the American Headache Association [5] and the American Congress of Obstetrics and Gynecology [6]. Several observational studies [7,8] and one prospective study [9] showed significant reductions in the number of headaches after changing from a standard regimen (21/7 day) to an extended regimen of COCs, suggesting that sustained levels of estrogen can prevent this subset of headaches. A recent comprehensive review by Edlow and Bartz [2] outlined this regard.

In a World Health Organization (WHO) Collaborative study concerning cardiovascular diseases and steroid hormone contraception, the adjusted risk of ischemic stroke was significantly correlated with migraine with aura, while there was no significant increase in women who experienced migraine without aura [10]. Similarly, a prospective study found a significant increase in strokes among migraineurs with aura, though the absolute risk was low 3.8 cases per 10,000 [4]. The additional risk of ischemic stroke attributable to women with migraines using COCs has been estimated as 8 per 100,000 women at age 20 years, and 80 per 100,000 women at age 40 years [11]. However, level 2 evidence from an US population-based case-control study of women with migraines who use COCs, showed a pooled-odds ratio of 2.08 (95\% CI, 1.19 to 3.65 ) for ischemic stroke [12]. A large Danish population-based case-control study found that among women with a history of migraine headaches, there was a threefold increase in the risk of stroke $(p<0.01)$ [13]. Neither of the studies differentiated between migraine with and without aura.

*Corresponding author: Jin Jun Luo, Departments of Neurology and Pharmacology, Temple University School of Medicine, 3401 North Broad Street, Suite C525, Philadelphia, PA 19140, USA, Tel: 1-215-707-3040; Fax: 1-215-7078235; E-mail: jluo@temple.edu

Received February 01, 2012; Accepted February 01, 2012; Published February 06, 2012

Citation: Dun EC, Luo JJ (2012) Can Migraines be Effectively Managed with Combined Oral Contraceptives? J Neurol Neurophysiol 3:e103. doi:10.4172/21559562.1000e103

Copyright: (c) 2012 Dun EC, et al. This is an open-access article distributed under the terms of the Creative Commons Attribution License, which permits unrestricted use, distribution, and reproduction in any medium, provided the original author and source are credited. 
Citation: Dababneh H, Guerrero WR, Khanna A, Peters K, Waters M (2012) Diffusion Weighted MRI Findings in Heparin Induced Thrombocytopenia (HIT). J Neurol Neurophysiol 3:122. doi:10.4172/2155-9562.1000122

Importantly, COCs are not suitable for all women with migraines. Because of the possibility of increased risk for ischemic stroke, it is recommended that the administration of COCs should be avoided in women migraineurs with aura, over 35 years, history of clotting disorder such as deep venous thrombosis, family history of heart attack or stroke under age 60 years, cardiovascular risk factors such as high blood pressure, high cholesterol, low HDL cholesterol, obesity, smoking and high-sensitivity C-reactive protein [14-16].

When prescribed within established guidelines, COCs could maximally benefit women with menstrual-related migraines and the estrogen effect may not impact on stroke risk.

\section{References}

1. Rasmussen BK, Jensen R, Schroll M, Olesen J (1991) Epidemiology of headache in a general population--a prevalence study. J Clin Epidemiol 44: 1147-1157.

2. Edlow AG, Bartz D (2010) Hormonal contraceptive options for women with headache: a review of the evidence. Rev Obstet Gynecol 3: 55-65.

3. Carolei A, Marini C, De Matteis G (1996) History of migraine and risk of cerebra ischaemia in young adults. The Italian National Research Council Study Group on Stroke in the Young. Lancet 347: 1503-1506.

4. Kurth T, Slomke MA, Kase CS, Cook NR, Lee IM, et al. (2005) Migraine, headache, and the risk of stroke in women: a prospective study. Neurology 64: 1020-1026.

5. http://www.AmericanHeadacheSociety.org

6. http://www.acog.org/
7. Allais G, Bussone G, Airola G, Borgogno P, Gabellari IC, et al. (2008) Oral contraceptive-induced menstrual migraine. Clinical aspects and response to frovatriptan. Neurol Sci 29 Suppl 1: S186-S190.

8. Sulak P, Willis S, Kuehl T, Coffee A, Clark J (2007) Headaches and ora contraceptives: impact of eliminating the standard 7-day placebo interval. Headache 47: 27-37.

9. Sulak PJ, Kuehl TJ, Ortiz M, Shull BL (2002) Acceptance of altering the standard 21-day/7-day oral contraceptive regimen to delay menses and reduce hormone withdrawal symptoms. Am J Obstet Gynecol 186: 1142-1149.

10. Donaghy M, Chang CL, Poulter N (2002) Duration, frequency, recency, and type of migraine and the risk of ischaemic stroke in women of childbearing age. J Neurol Neurosurg Psychiat 73: 747-750.

11. MacGregor EA, Guillebaud J (1998) Combined oral contraceptives, migraine and ischaemic stroke. Clinical and Scientific Committee of the Faculty of Family Planning and Reproductive Health Care and the Family Planning Association. Brit J Fam Plann 24: 55-60.

12. Schwartz SM, Petitti DB, Siscovick DS, Longstreth WT Jr, Sidney S, et al (1998) Stroke and use of low-dose oral contraceptives in young women: a pooled analysis of two US studies. Stroke 29: 2277-2284.

13. Lidegaard O (1995) Oral contraceptives, pregnancy and the risk of cerebra thromboembolism: the influence of diabetes, hypertension, migraine and previous thrombotic disease. Brit J Obstet Gynaecol 102: 153-159.

14. ACOG Practice Bulletin Number 73 (2006) Use of hormonal contraception in women with coexisting medical conditions. Obstet Gynecol 107: 1453-1472.

15. http://www.reynoldsriskscore.org

16. Medical eligibility criteria for contraceptive use (2009) (4thedn), Geneva Switzerland: World Health Organization. 